\title{
Swyer-James-Macleod Syndrome in a 10-Year-Old Boy Misdiagnosed as Asthma
}

Sir,

Swyer - James-Macleod syndrome or unilateral hyperlucent lung is a form of post infectious bronchiolitis obliterans that usually follows a viral or bacterial respiratory infection in infancy or early childhood. ${ }^{1,2}$ We describe a 10-yr-old boy with Swyer-James-Macleod syndrome who was misdiagnosed as asthma.

The boy was admitted with complaints of frequent cough, whitish expectoration, fever and dyspnea since 2 years of age. Since the last 5 years his dyspnea had significantly worsened during exertion. There was no personal or family history of asthma. He was diagnosed with asthma elsewhere and was variably treated for asthma without much relief to his symptoms, patient was born at term at home. At three days of age, he was admitted for ten days at a neonatal intensive care unit for pneumonia. There was no history suggestive of foreign body aspiration. He did not report recurrent infections involving other systems, coughing with food or change of body posture. His weight was $19.7 \mathrm{Kg}$ and height $130 \mathrm{~cm}$ and vital signs were within normal limits. ABG at room air showed $\mathrm{PaO}_{2} 74 \mathrm{mmHg}, \mathrm{PaCO}_{2} 38 \mathrm{mmHg}, \mathrm{pH} 7.38$ and $\mathrm{SpO}_{2} 96 \%$. Chest examination revealed flattening of left side with reduced movements on respiration. Coarse crackles were auscultated in left infrascapular area.

His complete hemogram and serum biochemistry were normal. Tuberculin skin test, HIV ELISA, sweat chloride test, ECG and ECHO, Immunoglobulin profile and GER scan were normal. Spirometry revealed airflow limitation as indicated, Patient (\%predicted): FVC 1.17L (88\%), FEV 0.86L (69.4\%) FEV 1 /FVC 73.3 (78\%), FEF 25-75\% 0.67L $(19 \%)$. Post bronchodilator readings were FVC $1.21 \mathrm{~L}$ (91\%), $\mathrm{FEV}_{1}$ 0.90L (72.6\%) $\mathrm{FEV}_{1} / \mathrm{FVC} 74.4$ (79\%), FEF 25$75 \%$ 0.59L (17\%). Bronchoalveolar lavage (BAL) fluid cytology and culture for bacteria, fungus and mycobacteria were negative. Chest radiograph revealed small and hyperlucent left lung with mediastinal deviation to the left. CT with contrast revealed reduced lung volume on left side with ipsilateral mediastinal shift and reduced pulmonary vascularity (Fig. 1). Cysticvaricose bronchiectasis was seen in the left lower lobe and small areas of mosaic attenuation in the adjoining pulmonary parenchyma. Right lung showed compensatory hyperinflation.

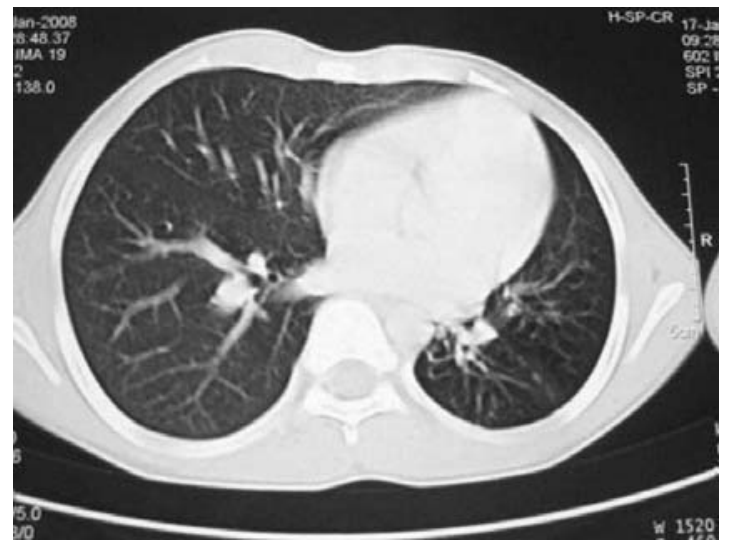

Fig. 1. CECT chest shows reduced pulmonary vascularity and lung volume on left side with ipsilateral mediastinal shift. Right lung shows compensatory hyperinflation. Small areas of mosaic attenuation seen on left side.

He was diagnosed as Swyer-James-Macleod syndrome and managed with chest physiotherapy for left bronchial drainage, low dose inhaled steroid (budesonide $200 \mu \mathrm{g}$ ) and inhaled bronchodilators. In last one year, he has had one episode of acute pulmonary exacerbation which was effectively managed with antibiotics, bronchodilators and chest physiotherapy.

We wish to highlight that patients not appropriately responding to asthma therapy should be worked up for alternative diagnosis and Swyer- James-Macleod syndrome should be considered as a differential diagnosis in patients with unilateral hyperlucent lung.

\section{Mandeep Walia, Vishnu Goyal and Pankaj Jain ${ }^{1}$ Department of Pediatrics, Chacha Nehru Bal Chikitsalaya, Delhi, ${ }^{1}$ Sri Anandpur Charitable Trust Diagnostic Centre, Delhi, India. \\ E-mail: mkwalia2000@yahoo.co.in [DOI-10.1007/s12098-010-0088-z]}

\section{REFERENCES}

1. Swyer PR, James GCW. A case of unilateral pulmonary emphysema. Thorax 1953; 8: 133-136.

2. Macleod WM. Abnormal transradiancy of one lung. Thorax 1954;9:147-153. 